\title{
APLICAÇÃO DA GENÉTICA MOLECULAR PARA A MELHORIA DA QUALIDADE DA CARNE BOVINA
}

\author{
Application of molecular genetics to improving the quality of beef \\ Jackeline Karsten Kirinus', Ana Paula Burin Fruet² ${ }^{2}$ César Teixeira ${ }^{3}$, Andrea Cristina Dörr ${ }^{4}$, José Laerte Nör- \\ nberg $^{5}$ \\ 'Profa . Efetiva do Departamento de Medicina Veterinária, Campus Xanxerê II, Universidade do Oeste de Santa Catarina (UNOESC), Xan- \\ xerê, Santa Catarina, Brasil \\ ²UFSM - Aluna de mestrado do Programa de Pós-graduação em Ciência e Tecnologia de Alimentos (PPGCTA), Centro de Ciências Rurais \\ (CCR), Universidade Federal de Santa Maria (UFSM), Santa Maria, Rio Grande do Sul, Brasil. \\ ${ }^{3}$ Advogado e Mestre em Direito Ambiental pela Universidade de Zaragoza (Espanha). Doutorando em Direito Civil pela Universidade de \\ Zaragoza. \\ ${ }^{4}$ Prof ${ }^{\text {a }}$. Adjunto do Departamento de Ciências Econômicas, CCR, UFSM, Santa Maria, Rio Grande do Sul, Brasil. \\ ${ }^{5}$ Profo. Adjunto do Departamento de Tecnologia e Ciência dos Alimentos (DTCA), CCR, UFSM, Santa Maria, Rio Grande do Sul, Brasil.
}

\section{Resumo}

A bovinocultura de corte representa grande importância econômica no contexto mundial e nacional. Os objetivos deste trabalho é revisar alguns aspectos relevantes da aplicação da genética molecular para a melhoria da qualidade da carne bovina com vistas à definição de qualidade do produto cárneo e de mercados consumidores mais exigentes. Tendo em vista a necessidade do mercado consumidor em avaliar a carne produzida, faz-se necessário conhecer as características econômicas do produto a ser consumido, assim como padronizar e implementar técnicas mais sofisticadas para a avaliação das propriedades reológicas da carne. Neste contexto, devido aos inúmeros processos bioquímicos no qual estão envolvidos os sistemas de ativação de enzimas proteolíticas e a degradação das proteínas miofibrilares, os métodos moleculares vêm sendo utilizados como ferramenta para a avalição genética dos fatores que influenciam a maciez da carne bovina.

Palavras-chave: marcadores moleculares, PCR, SNPs.

\begin{abstract}
The beef cattle industry is of great economic importance in global and national context. The objectives of this paper is to review some important aspects of the application of molecular genetics to improving the quality of beef with a view to defining quality of meat product and more demanding consumer markets. Considering the need of the consumer market to assess the meat produced, it is necessary to know the economic characteristics of the product to be consumed, as well as standardize and implement more sophisticated techniques for the evaluation of the rheological properties of meat. In this context, due to the numerous biochemical processes which are involved in the activation systems of proteolytic enzymes and degradation of myofibrillar proteins, molecular methods are being used as a tool for rating the genetic factors that influence the tenderness of beef.
\end{abstract}

Keywords: marker molecular, PCR, SNPs. 


\section{INTRODUÇÃO}

O setor bovino forma hoje uma importante cadeia do agronegócio, com forte interação dos setores ligados ao agronegócio, genética, comércio, cultura e turismo, sendo uma das cadeias produtivas que mais oferece oportunidades de trabalho, conquistando posição de destaque na economia mundial.

Segundo a USDA (2013), os principais fatores que contribuem para o aumento da produção de carne bovina são: o maior número de exportações; crescimento contínuo na demanda doméstica por carne bovina; maior poder de compra dos consumidores, o que levará ao maior consumo de proteína animal e fatores como pesos levemente maiores de carcaças, aliados das melhorias genéticas e de nutrição.

De modo geral, a bovinocultura de corte é um dos setores que mais cresce na economia mundial, impulsionada pelo crescimento da renda e amparada pela mudança estrutural e tecnológica. No entanto, são necessários investimentos contínuos em aspectos sanitários, inocuidade dos alimentos de origem animal, inspeção, biossegurança e bem-estar animal para melhorar a produtividade e garantir uma adequada sustentabilidade no futuro.

Este trabalho tem por objetivo revisar alguns aspectos importantes da aplicação da genética molecular para a melhoria da qualidade da carne bovina. Assim, serão abordados temas relacionados as perspectivas dos consumidores por produtos cárneos de qualidade, aplicação da genômica na seleção de raças, fatores que afetam o processo de amaciamento da carne bovina, principais genes descritos na literatura e sua relação com a maciez, além de perspectivas da aplicação genética para melhoria da qualidade da carne bovina.

\section{BUSCA POR PRODUTOS DE QUALIDADE}

A qualidade da carne é considerada como complexa e multivariante; podendo ser influenciada por múltiplos fatores e suas interações, entre eles: raça, sexo, idade, alimentação, manejo prévio ao abate, método de insensibilização e sangría, assim como, resfriamento, conservação e genética (ANDERSON et al., 2005). Desta forma, analisar como estes fatores influem nos mecanismos biológicos; e qual a sua relação com os parâmetros específicos de qualidade é importante para compreender os processos físicos e fisiológicos que possibilitam a transformação do músculo em carne, em nível genético e protéico, o que possibilitará a seleção de novas estratégias e indicadores de maciez da carne bovina.

Entretanto, o problema da "obtenção da qualidade da carne" não é fácil de solucionar (SAÑUDO et al., 2008). Este não é devido somente aos interesses mencionados dos diferentes grupos da cadeia, senão também a própria "fragilidade do produto" devido a complexidade de sua composição e estrutura, além da falta de estabilidade intrínseca e da multiplicidade de fatores que influem suas características e qualidades, desde o momento antes do nascimento do animal, até o momento final do consumo.

Assim, as marcas de qualidade são uma realidade parcial no mercado e no futuro serão uma necessidade com o objetivo de fidelizar o consumidor (CAÑEQUE; SAÑUDO, 2005). No entanto, a credibilidade de uma marca de qualidade em produtos cárneos e a própria fidelidade do consumidor a estes, somente se constitui na medida em que encontra suporte científico, o qual valide tais atributos como: aspectos físico-químicos, sensoriais, funcionais e genéticos de um determinado produto.

\section{PROCESSO DE AMACIAMENTO DA CAR- NE BOVINA}

O amaciamento da carne é um processo que merece grande atenção dos pesquisadores, pois atualmente tem crescido a exigência dos consumidores por produtos de qualidade. Grande parte do processo de amaciamento da carne post mortem ocorre durante a estocagem refrigerada, ou maturação, e consiste na proteólise dos componentes estruturais das proteínas miofibrilares presente no tecido muscular.

Sabe-se que carnes com alta atividade de calpastatina no primeiro dia post mortem são menos macias, ou seja, necessitam de maior força para serem cortadas (GOLL, 2003). Desta forma, o modelo proposto por DRANSFIELD (1993) vem confirmar que a inibição das calpaínas pela ação da calpastatina e a inativação de calpaínas e calpastatinas por autólise, ocorre na medida em que se dá o amaciamento da carne. Portanto, a calpastatina é o inibidor da ação da calpaína durante o processo de proteólise post mortem (CASAS et al., 2005; GEESINK et al., 2006).

Assim, têm-se que todas as células de mamíferos contêm um sistema proteolítico dependente de cálcio, composto pela protease endógena cal- 
paína e seu inibidor, a calpastatina (LEE et al., 2000). No entanto, tendo em vista as dificuldades encontradas para se entender todo o processo bioquímico no qual estão envolvidas a ativação de enzimas proteolíticas e a degradação das proteínas miofibrilares, os métodos moleculares vêm conquistando espaço neste contexto (PAGE et al., 2002; PAGE et al., 2004).

\section{APLICAÇÃO DA GENÔMICA NA BOVI- NOCULTURA}

Umas das estratégias propostas pela FAIP (Farm Animal Industrial Plattform, 2003) é incorporar a genômica nos processos de seleção de raças. A genômica é capaz de gerar novas hipóteses biológicas que podem ser estudadas com mais detalhes (HOCQUETTE et al., 2007). Estes métodos possibilitam maior impacto na avaliação de características complexas, que são afetadas por interações entre diferentes genes com pequenos efeitos. Por exemplo, as características do tecido conjuntivo, conteúdo de gordura, composição das fibras musculares e maturação da carne são consideradas fatores biológicos complexos.

A identificação individual de bovinos mediante a utlização do DNA é um importante instrumento para controlar e autentificar os sistemas tradicionais (número de tatuagem, brincos, sistemas eletrônicos). Esta vantagem é atribuida ao fato de que a informação genética contida no indivíduo é inalteravél durante toda a sua vida, além de ser única em cada animal e de estar presente em cada parte do seu organismo (sangue, tecidos, folículos pilosos, sêmen). Assim, uma análise genômica possibilita maior objetividade, repetibilidade e segurança quando comparados aos sistemas de identificação tradicionais (FRYLINCK et al., 2009; PICARD et al., 2010; GUILLERMIN et al., 2011).

Neste contexto, é importante verificar as normas estabelecidas pelo Ministério da Agricultura, Pecuária e Abastecimento, órgão responsável por emitir as autorizações e registros, além de fiscalizar produtos e derivados destinados a uso animal, na agricultura, pecuária, agroindústria e áreas afins, de acordo com a legislação em vigor e segundo o regulamento da Lei 11.105, de 24 de março de 2005 (BRASIL, 2005).

Além disso, fatores ambientais também apresentam contribuição para a variação da maciez da carne bovina. Dentro de uma raça, a genética controla $30 \%$ da variação da maciez, que representa a herdabilidade (efeito de genes aditivos) desta característica. Por outro lado, $70 \%$ da variação é explicada por fatores ambientais e efeito de genes não aditivos. Desta forma, têm-se que entre raças, esta varição é igual ou menor que dentro de uma só raça (KOCH et al., 1982).

No entanto, outros autores constataram que em bovinos, aproximadamente $40 \%$ da variação da maciez é de origem genética e $60 \%$ de origem ambiental, sem levar em conta o efeito da raça. Isto significa, que entre raças ou dentro de uma mesma raça, a maciez pode ser controlada por fatores ambientais, como por exemplo: alimentação, tempo de engorda, estresse, maturação da carcaça, método de cocção, entre outros (HOCQUETTE et al., 2007).

Portanto, a utilização de marcadores moleculares auxilia na previsão precoce do potencial genético do animal para produção de uma carne com alta qualidade, além de tornar dispensável o abate do animal para avaliação fenotípica.

\section{MARCADORES MOLECULARES RELACIO- NADOS COM A MACIEZ DA CARNE BOVI- NA}

A variabilidade das características musculares dos animais explica somente entre um terço e um quarto da variabilidade encontrada na maciez, devido a esta ser uma característica de difícil mensuração (RENAND et al., 2001). Isto sugere que outras características musculares, sem identificação até o momento, contribuam em grande parte para a variabilidade total (BERNARD et al., 2007). Desta forma, a maciez da carne bovina representa um conjunto complexo de diferentes vias celulares, onde os estudos de genômica mostram que muitas proteínas podem ser consideradas como importante marcadores desta característica (GUILLERMIN et al., 2011).

Diversos marcadores moleculares (toda e qualquer característica herdável presente no DNA e que diferencia dois ou mais indivíduos) associados a genes responsáveis pela maciez apresentam grande importância para o setor cárneo. Segundo Cañeque e Sañudo (2005), um marcador de DNA, para ser utilizado em identificação genética e em sistemas de rastreabilidade, necessita reunir as seguintes características:

a)ser polimórfico, ou seja, apresentar diferentes formas genéticas (alelos) em uma população que permita diferenciar indivíduos;

b)ser estável, para que as mutações não possam influenciar os resultados; 
c)seleccionar marcadores distribuídos no mesmo gene;

d)ser de domínio público, e não ser submetido a nenhum tipo de patente, o que impeça sua reprodução e aplicação;

e)ter um baixo custo financeiro, tanto na obtenção quanto na aplicação das técnicas para análises;

f)ser interpretado de forma fácil e objetiva;

g)requerer pouca quantidade e qualidade de material para análise de DNA;

h)ser facilmente reproduzido em diferentes laboratórios, assim como proporcionar o intercâmbio de informações de animais analisados em distintos locais;

i)ser passível de automatização para aumentar o rendimento e baixar os custos financeiros.

Assim, a utilização de marcadores moleculares para diagnóstico permite uma previsão precoce do potencial genético do animal para produção de carne com alta qualidade, além de tornar dispensável o abate do animal para avaliação fenotípica.

Em biologia molecular, a principal técnica utilizada para a detecção de marcadores moleculares baseia-se na reação em cadeia da polimerase (PCR), que permitiu a automação e a simplificação das etapas de obtenção dos padrões genotípicos (CASSAR-MALEK et al., 2008). Nessa técnica, fragmentos de DNA específicos são replicados in vitro e isso resulta na produção de milhares de cópias da sequência desejada, em quantidade suficiente para permitir a visualização do DNA, sem a necessidade de métodos indiretos. Ainda, pode-se ressaltar a análise de SNPs é amplamente utilizada para a verificação das mutações.

Os primeiros métodos de biologia molecular de alto rendimento a serem desenvolvidos foram métodos de sequenciamento. Portanto, a sequenciação de genomas de muitas espécies foi alcançada, ou está em progresso. Isto facilitou melhor a compreensão da estrutura do genoma e a identificação de polimorfismos (principalmente o SNP), que permitiram o mapeamento genético mais preciso. Na ciência carne bovina, isto contribuirá para uma identificação mais rápida de marcadores genéticos que serão úteis para a reprodução animal, com o objetivo de melhorar a qualidade de carne (HOCQUETTE et al., 2007).

Neste sentido, é importante manter-se atualizado com as pesquisas globais nessa área, buscando uma aplicação prática desses trabalhos a fim de caracterizar e controlar melhor a carne bovina produzida. Portanto, os métodos moleculares constituem-se uma alternativa à caracterização fenotípica tradicional, que muitas vezes apresentam subjetividade nos resultados. Além disso, inúmeros estudos que vêm sendo realizados em bovinos propõem a existência de uma associação dos genes da calpaína e calpastatina com a maciez da carne bovina.

\section{I Calpaína}

No contexto molecular, o gene da calpaína (CAPN) codifica para $\mu$-calpaína e está localizado no cromosoma 29 (BTA 29) de bovinos (CASAS et al., 2005). Diversos marcadores moleculares do gene CAPN foram relacionados ao processo de seleção hereditária em Bos indicus e Bos taurus, onde relatou-se um alto nível de significância deste gene com a força de cisalhamento da carne bovina.

Page et al. (2002) avaliaram dois SNPs do gene CAPN1. O primeiro, localizado no marcador CAPN1_316 (exon 9) que altera a sequência da proteína por substituição dos aminoácidos alanina/ glicina no domínio II e influencia o peptídeo final; e o segundo, marcador CAPN1_530 (exon 14), que afeta a cadeia de aminoácidos no domínio III da proteína na substituição de isoleucina/valina.

Por outro lado, White et al. (2005) mostrou que o marcador de maciez CAPN1_4751 (intron 17) tem relação tanto para Bos taurus e Bos indicus assim como para seus descendentes híbridos, e concluiu que os marcadores 316 e 4751 são preferidos como uma ferramenta para guiar a seleção, porque mostram a associação de maciez em uma grande variedade de populações quando comparados ao marcador 530 . O mesmo autor afirma que os marcadores CAPN1_4753 e CAPN1_5331 não apresentaram frequências satisfatórias em amostras oriundas de animais Bos taurus.

Desta forma, segundo alguns autores pode-se sugerir que a variação genética do marcador CAPN1_4751 em Bos indicus está associada com a variação da força de cisalhamento em 7 e 21 dias post mortem. White et al. (2005) associou o alelo $\mathrm{T}$ com os maiores valores da força de cisalhamento e com a maior frequência nos animais Bos indicus. Este marcador foi, portanto, também testado em raças Bos taurus, onde o alelo mais frequente foi o C, associado aos menores valores da força de cisalhamento.

Costello et al. (2007) encontraram resultados semelhantes em relação marcador 316 , mas conflitantes para o marcador 530. Entretanto, Frylinck et al. (2009) afirma que os marcadores 
316 e 530 da calpaína podem ser usados como guia de seleção em Bos taurus, mas não apresentam altas frequências em bovinos da raça Brahman (Bos indicus).

Por outro lado, estudos recentes realizados por Barendse et al. (2008) encontraram significativos efeitos de substituição em haplótipos de três raças: Brahman, Belmont Red e Santa Gertrudis. Este autor sugere que os marcadores estudados (CAPN3, APN3), localizado em BTA 10, podem ser responsáveis por parte da diferença global entre as raças taurina e zebuínas na maciez da carne. Acredita-se que a maior variabilidade na maciez da carne foi encontrada nas raças zebuínas e cruzas; tal afirmativa, sugere que nenhum desses SNPs testados são mutações causais.

\subsection{Calpastatina}

O gene da calpastatina (CAST), mapeado em BTA 7, por Bishop et al. (1993) é considerado um gene candidato para a maciez da carne. No entanto, estudos iniciais não detectaram associação significativa de polimorfismos para a maciez da carne (LONERGAN et al., 1995; CHUNG et al., 1999). Pode-se constatar que em ambos os estudos, o tamanho amostral era pequeno, o que pode ter contribuído para a não identificação das associações.

Em 2001, Chung et al. (2001a) identificou pela primeira vez a alteração genética no domínio L do gene CAST bovino no intron 6 (acesso Genbank número L14450); e mais tarde, os resultados indicaram que a utilização da genotipagem deste marcador permitiria a identificação de animais com atividade enzimática favorável de calpastatina e características da carcaça (CHUNG et al., 2001b).

No âmbito mundial, Barendse (2002) identificou e patenteou um SNP caracterizado pela transição de uma adenina por uma guanina na região 3 'UTR do gene calpastatina, o CAST_2959 (exon 30). Este polimorfismo tem sido utilizado em técnicas de genotipagem utilizando espectrometria de massa e de associações significativas com as características relacionadas à qualidade da carne de bovinos de corte (CASAS et al., 2006; MORRIS et al., 2006). Além disso, o mesmo já foi descrito em técnicas de PCR-RFLP através da análise do mapa de restrição da sequência, uma vez que está localizado no sítio de reconhecimento da enzima Dde I (CURI et al., 2008). A predominância do alelo A em CAST_2959 foi relatada por Curi et al. (2009) e Ribeca et al. (2012).

Outro SNP, o CAST_UoG (intron 5) foi reportado por Schenkel et al. (2006), este é um produto de substituição de uma guanina por uma citosina na base 282 do gene CAST e seu nome deriva da University of Guelph (Guelph, Ontario, Canadá) onde se realizaram estudos com este marcador (www.uoguelph.ca). Foi verificado uma maior frequencia para o alelo $\mathrm{C}$, do que do alelo $\mathrm{G}$, e desta forma, os autores sugerem que animais com o haplotipo CC teriam uma carne mais macia nos período post mortem, além de evidenciar esse SNP como elemento que afeta outras importantes características de carcaça, tais como a produção de gordura.

Em estudos de associação de polimorfismos da calpastatina em animais da raça Piemontese, Ribeca et al. (2013) encontraram menores frequências para o alelo G no SNP CAST_UoG (base 282), localizado no intron 5. Todavia estes resultados estavam de acordo com os relatados em um estudo anterior sobre o gado Piemontese (LISA; DI STASIO, 2009). Também, Pinto et al. (2010) encontraram resultados muito semelhantes para polimorfismos e testes de associação com os valores obtidos para CAST_UoG e CAST_WSU.

Outro SNP da calpastatina relacionado com as características de qualidade da carne é o CAST_2870, localizado no exon 30 da região 3'UTR do gene. Corva et al. (2007) encontrou maior frequência do alelo $G$ em uma população de cruzamento de animais Angus e Hereford. O mesmo resultado foi obtido por Ribeca et al. (2013) em animais da raça Piemontese.

Portanto, com relação as aplicações moleculares, pode-se visualizar em estudo realizado na Argentina, no "Sumário Consolidado de touros Angus do Mercosul_2012" (Figura 1), que indivíduos com variantes alélicas (genéticas) mais favoráveis (+) para os marcadores da calpaína e calpastatina apresentam uma forte correlação significativa ( $p<0,001)$ com a maciez da carne, medida por WBSF (1 quilograma menos de força de corte). Por simplicidade, a variante alélica de maior maciez se identifica como $(+)$ e a de menor maciez como (-). Desde modo, para cada marcador, os animais podiam ser ++ (homozigotos para maior maciez), -- (homozigotos para menor maciez), ou +- (heterozigotos). O genótipo mais favorável para a maciez (6 positivos) para CAST_2959, CAPN1_316, CAPN1_4751 foi ++ ++ ++ , respectivamente, enquanto o menos favorável foi -- -- --. Dentro destas variantes extremas têm-se 27 possíveis combinações que indicam maior ou menor maciez (ou força de corte) de acordo como se apresentam estes três marcadores em 
um reprodutor particular. O marcador molecular CAST_2959 é utilizado pela empresa australiana GeneSTAR $\AA$, enquanto a empresa americana Igenity ${ }^{\circledR}$ utilizada o CAST_UoG. Em consequencia, todo o expressado anteriormente é válido, somente foi necessário substituir o CAST_2959 por CAST_UoG. Isto significa, que a diferença de menor força de corte é a mesma (um quilograma), independente do marcador molecular que foi usado para a calpastatina, sempre e quando o genótipo combinado for o mais favorável $(++++++)$ com respeito ao menos favorável (-- -- --).

\begin{tabular}{|c|c|c|c|c|c|c|c|c|c|c|c|c|}
\hline \multirow[b]{2}{*}{ Nombre } & Peqistro & $\overline{\text { Nacer }}$ & Destete & Leche & Final & C.E. & A.0.B. & E.Q.D. & Tern: & Tezal & (S.A & AM. \\
\hline & CP Año & ${ }_{\mathrm{NH}}^{\mathrm{DEP}}{ }_{\mathrm{Accu}} \mathrm{Per}$ & ${ }_{\mathrm{NH}}^{\mathrm{DEP}}{ }_{\mathrm{AcCu}} \mathrm{Per}$ & NN $\underset{\text { Accu }}{\text { DEP }}$ Per & $\begin{array}{c}\mathrm{NH} \\
\mathrm{Accu}\end{array}$ & NH ${ }_{\text {Accu }}^{\text {DEP }}$ & $\begin{array}{c}\text { NH } \\
\text { Accu }\end{array}$ & $\begin{array}{c}\text { NH } \\
\text { Accu }\end{array}$ & $\begin{array}{l}\text { CAST) } \\
2569 \\
\text { il }\end{array}$ & $\begin{array}{l}\text { CAST } \\
\text { UoG }\end{array}$ & $\begin{array}{c}\text { CAPN } \\
316\end{array}$ & CAP \\
\hline Toro A & $\begin{array}{r}724509 \\
\text { ARG } 2004\end{array}$ & $\begin{array}{ll}528 & -1.4 \\
0.99\end{array}$ & $509 \begin{array}{c}+8.6 \\
0.98\end{array}$ & $400 \begin{array}{l}+6.7 \\
0.93\end{array}$ & $\begin{array}{c}286+14.9 \\
0.94\end{array}$ & $121 \begin{array}{l}+1.2 \\
0.96\end{array}$ & $11 \begin{array}{cc}-0.6 & \\
& 0.56\end{array} 6$ & $11_{0.57}^{-0.0} 5$ & +- & +- & +- & \\
\hline Toro B & $\begin{array}{r}0077835 \\
\text { BRA } 2003\end{array}$ & $419_{0.97}^{+0.2} \quad 62$ & $394 \underset{0.95}{+5.2}$ & $233{ }_{0.91}^{-1.1} 64$ & $307 \begin{array}{cc}+9.3 & \\
& 0.91\end{array}$ & $134{ }_{0.94}^{0.0} 47$ & $58 \begin{array}{r}3.7 \\
0.89\end{array}$ & $58{ }_{0.90}^{-0.6}$ & & & & \\
\hline
\end{tabular}

Figura 1. Como interpretar o sumário de pais Angus consolidado do Mercosul.

Todavia, o efeito destes genes não explica a totalidade da variabilidade genética da característica estudada. Além disso, em algumas raças estes alelos são fixos e a variabilidade da característica não esta atribuída aos mesmos. Nestes casos, é possível que outros genes sejam responsáveis por esta variabilidade. Entre eles, destaca-se a chaperoninas (heat shock proteins, HSP), que são proteínas protetoras que participam em mecanismos de apoptose celular; e a leptina, relacionada com a deposição de gordura.

\subsection{Chaperoninas (heat shock proteins, HSP)}

As chaperonas, co-chaperonas e "Heat Shock Factors" constituem a maquinaria celular para a manutenção correta da conformação das proteínas, cujo o bom funcionamento depende da correta forma da sua estrutura tridimensional (FINK, 1999).

As chaperonas são estimuladas por fatores de estresse (temperatura, umidade, hipoxia, entre outros) devido a mudança na conformação e desnaturalização das proteínas celulares. Elas podem atuar tanto na recuperação da conformação natural das proteínas, como na realização de outras funções celulares até agora desconhecidas. É possível que também estejam relacionadas aos processos de maciez, pois formam um complexo ativo com as caspases, impedindo suas funções; além de proteger proteínas diana, impedindo sua degradação e reparando as estruturas iniciais e ativas de proteínas que tenham sofrido danos estruturais (PICARD et al., 2010; GUILLERMIN et al., 2011).

Também, foi encontrado outro gene (HSPB1) que codifica uma chaperona (HSP27), ela foi relacionada com a dureza da carne, a resistên- cia do estresse e a organização da actina. Estudos recentes, demonstraram que esta chaperona têm ação anti-apoptótica, além de ser capaz de atuar em componentes importantes da rota de sinalização, como por exemplo, a ativação das caspases (YOU et al., 2012). Por outro lado, Ouali et al. (2006) detectaram uma relação das chaperonas HSP70, HSP27 com a maciez da carne bovina.

Dependendo da maciez da carne, 146 genes podem ser expressos de forma diferente em bezerros de idades variadas (BERNARD et al., 2007). Destes, destacam-se o gene DNAJA1, que tem uma forte correlação negativa com a maciez e explica $63 \%$ da variabilidade. Este gene codifica uma chaperona de $40 \mathrm{KDa}$, a HSP40 (GUILLERMIN et al., 2011), que por sua vez apresenta grande influência na maciez da carne bovina, classificada como uma família de proteínas conservadas responsáveis pela manutenção de funções celulares essenciais a vida, como o empacotamento protéico e apoptose celular. Assim, tem-se que as chaperoninas da família HSP, como as HSP40 e HSP70, são proteínas de choque térmico associadas ao estresse e condições ambientais, também conhecidas como "heat shock proteins" (FINK, 1999; OUALI et al., 2006).

Finalmente, outra chaperona, $\mathrm{a} \square \mathrm{B}$-cristalin codificada pelo gene CRYAB, relacionada com a maciez da carne (SUN; MACRAE, 2005). Esta chaperona está relacionada com a proteção dos filamentos intermediários, estabilização e proteção de proteínas diana impedindo sua agregação irreversível (BERNARD et al., 2007).

\subsection{Leptina}

Em bovinos, a leptina controla a deposição de gordura subcutânea e intramuscular, afeta a terminação do animal para peso de abate e a 
palatabilidade da carne, aumentando a maciez e a suculencia da carne (HAEGEMAN et al., 2000; BUCHANAN et al., 2002; GEARY et al., 2003).

Devido a sua importância, Lara et al. (2011) sugerem que o SNP305 pode auxiliar na identificação de animais com potencial para produção de carcaças com acabamento satisfatório, além de afetar indiretamente a qualidade da carne bovina.

\subsection{Kits comerciais}

Recentemente, testes para detectar a presença de mutações associadas com a maciez da carne bovina e que utilizam polimorfismos genéticos do genes da calpastatina e/ou calpaína foram disponibilizados por empresas privadas.

O primeiro comercialmente testado foi o GeneSTAR (Genetic Solutions Pty. Ltd., Albion, Austrália), um teste de sensibilidade utilizado para detectar a substituição G/A (AF159246, base 2959) localizada a região 3'UTR do SNP CAST_2959.

O segundo teste foi TenderGENETM IGENITY (Merial Ltd., Atlanta, GA), utilizado para detectar a mutação de substituição G/C (AY008267, base 282), localizado no intron 5 do SNP CAST_UoG do genoma bovino (SCHENKEL et al., 2006).

\section{PERSPECTIVAS GENÔMICAS}

Ainda no contexto anterior, Guillermin et al. (2011) relatou três proteínas, nunca antes estudadas em relação a maciez, são elas: SUMO4 (GUO et al., 2005), H2AFX (YANG et al., 2010) e TP53 (GRIGORIAN et al., 2001). Estas proteínas são caracterizadas por certas funções de regulação e podem ser responsáveis para o equilíbrio entre as vias de apoptose ou estresse. Este trabalho também identificou caminhos celulares fortemente envolvidos nos processos de amaciamento da carne: apoptose, funções HSP e resistência ao estresse oxidativo; e por fim ressalta que o papel destas vias é diferente entre os tipos de músculos.

Logo, pode-se constatar que é difícil ter uma visão geral do atributo maciez em termos de vias celulares. Nos últimos anos, muitos estudos têm sido realizados para a compreensão dos processos biológicos que contribuem para a maciez da carne bovina. Em particular, a utilização de técnicas de genômica funcional que revelem genes ou proteínas tal como marcadores moleculares de qualidade sensorial da carne (maciez, sabor, suculência).

A utilização da genômica funcional permite pesquisar centenas de marcadores biológicos de maciez, milhares de genes ou proteínas a fim de estabelecer uma lista com possíveis potenciais marcadores de maciez, e incluso possibilitar o desenvolvimento de marcadores moleculares por seleção assistida (MAS) através dos métodos de seleção genômica ou melhorias para a predição da qualidade da carne.

Cabe salientar que os estudos já mencionados dos marcadores (CAPN1 e a CAST) explicam somente $20 \%$ da variância genética aditiva. No entanto, este valor já representa um grande avanço para a seleção objetiva de animais pelo atributo de maciez da carne bovina, tendo em vista que pode-se realizar por exemplo, um estudo em nível populacional. Neste sentido, por exemplo, as frequências gênicas obtidas pelas variantes favoráveis $(+)$ do marcador CAST_2959, marcador CAPN1_316 e do marcador CAPN1_4751 podem possibilitar abrir novas expectativas e ferramentas de trabalho com os MAS a fim de selecionar animais com característica desejável de maciez, atributo este mais exigido pelos consumidores de carne bovina, tanto no mercado interno como no externo.

Por sua vez, sabe-se que a eficiência reprodutiva é a característica mais importante em bovinos de carne; atualmente, existem inúmeros avanços através da utilização das DEPs de certas características quantitativas associadas, em parte para esta eficiência (peso ao nascer, facilidade de parto, circunferência escrotal, etc.). No entanto, muito pouco se avançou através da avaliação genômica, mas as expectativas são muito promissoras a médio prazo.

Portanto, os genes (DNAJA1, HSPB1 e $C R Y A B$ ), junto com a CAPN e a CAST (Quadro 1) podem ser considerados possíveis candidatos relacionados com a maciez, uma vez que encontraram-se variantes genéticas com efeito significativo sobre esta característica. Assim, estes genes poderiam ser inseridos em programas de marcadores genéticos como certificadores das raças estudadas na busca com um produto de qualidade diferenciada. 
Quadro 1. Principais marcadores moleculares da calpaína (CAPN1) e calpastatina (CAST) relacionados com a maciez da carne bovina

\begin{tabular}{|c|c|c|c|c|c|c|}
\hline Gene & Marcadores & $\begin{array}{l}\text { Referencia } \\
\text { autor, ano }\end{array}$ & $\begin{array}{l}\text { Local do } \\
\text { estudo }\end{array}$ & $\begin{array}{c}\text { Posição no } \\
\text { BTA }\end{array}$ & $\begin{array}{c}\text { Número de } \\
\text { acesso no } \\
\text { GenBank e } \\
\text { posicão da base }\end{array}$ & $\begin{array}{l}\text { Localização e } \\
\text { mutação (SNP) }\end{array}$ \\
\hline \multirow[t]{6}{*}{ CAPN } & CAPN1_316 & Page et al., 2002 & $\begin{array}{c}\text { USA e Nova } \\
\text { Zelândia } \\
\end{array}$ & BTA29 & $\begin{array}{c}\text { AF252504, base } \\
5709 \\
\end{array}$ & Exon 9 - C/G \\
\hline & CAPN1_530 & Page et al., 2002 & $\begin{array}{c}\text { USA e Nova } \\
\text { Zelândia } \\
\end{array}$ & BTA29 & \begin{tabular}{|c|} 
AF248054.2, base \\
4558 \\
\end{tabular} & Exon $14-\mathrm{A} / \mathrm{G}$ \\
\hline & CAPN1_530 & Page et al., 2002 & $\begin{array}{c}\text { USA e Nova } \\
\text { Zelândia } \\
\end{array}$ & BTA29 & \begin{tabular}{|c|} 
AF248054.2, base \\
4558 \\
\end{tabular} & Exon $14-\mathrm{A} / \mathrm{G}$ \\
\hline & CAPN1_4753 & \begin{tabular}{|c} 
Casas et a1. \\
2005 \\
\end{tabular} & USA & BTA29 & \begin{tabular}{|c|} 
AF248054.2, base \\
8676 \\
\end{tabular} & Intron 21- A/C \\
\hline & CAPN1_5331 & \begin{tabular}{|c} 
White et al. \\
2005 \\
\end{tabular} & USA & BTA29 & \begin{tabular}{|c|} 
AF252504.2, base \\
327 \\
\end{tabular} & Intron $1-\mathrm{A} / \mathrm{T}$ \\
\hline & CAPN3, APN3 & Barendse, 2008 & Austrália & BTA10 & \begin{tabular}{|c|} 
AF115744.1, base \\
$1538+225$ \\
\end{tabular} & Exon 6 - G/T \\
\hline \multirow[t]{4}{*}{ CAST } & CAST_UoG & \begin{tabular}{|c} 
Schenkel et al., \\
2006 \\
\end{tabular} & Canadá & BTA7 & \begin{tabular}{|c|} 
AY008267, base \\
282
\end{tabular} & Intron $5-\mathrm{G} / \mathrm{C}$ \\
\hline & CAST_WSU & $\begin{array}{c}\text { Garcia et al., } \\
2006\end{array}$ & USA & BTA7 & $\begin{array}{c}\text { AY008267, base } \\
263\end{array}$ & Exon $4-\mathrm{C} / \mathrm{T}$ \\
\hline & CAST_2870 & $\begin{array}{c}\text { Corva et al., } \\
2007\end{array}$ & Argentina & BTA7 & $\begin{array}{c}\text { AF159246.1 } \\
\text { base } 2870\end{array}$ & $\begin{array}{c}\text { Exon 30_3'UTR } \\
-\mathrm{A} / \mathrm{G}\end{array}$ \\
\hline & CAST_2959 & $\begin{array}{l}\text { Barendse, } \\
2002\end{array}$ & Austrália & BTA7 & $\begin{array}{c}\text { AF159246.1, } \\
\text { base } 2959\end{array}$ & $\begin{array}{c}\text { Exon 30_3'UTR } \\
- \text { A/G }\end{array}$ \\
\hline
\end{tabular}

\section{CONCLUSÃO}

A maciez da carne é uma característica estritamente relacionada com a aceitabilidade do produto por parte dos consumidores e, por conseguinte, a seleção genética tem sido utilizado para a sua melhoria. Neste sentido, busca por marcas de qualidade constitui-se em uma exigência do mercado consumidor.

Diversos programas de avaliação genética em bovinos de corte têm sido empregados, principalmente com ênfase às características reprodutivas, de crescimento e certificação. Contudo, características de carcaça, como o grau de textura e maciez não são rotineiramente contempladas nesses programas, provavelmente, em razão das dificuldades de mensuração.

Além disso, a variação bioquímica intermuscular da maciez da carne não está completamente compreendida. Deste modo, analisar os principais genes candidatos com importantes funções no metabolismo animal, pode ajudar a identificar potenciais marcadores moleculares na produção de bovinos.

\section{REFERÊNCIAS}

ANDERSON, R.V. et al. An evaluation of production and economic efficiency of two beef systems from calving to slaughter. Animal Science, v. 84, p. 694-704, 2005.

BARENDSE, W. et al. Variation at the Calpain 3 gene is associated with meat tenderness in zebu and composite breeds of cattle. BMC genetics, v. 9, n. 1, p. 41, 2008.

BARENDSE, W. DNA markers for meat tenderness. International patent application PCT/AU02/00122. International patent publication WO 02/064820 A1. 2002.

BERNARD, C. et al. New indicators of beef sensory quality revealed by expression of specific genes. Journal of Agricultural and Food Chemistry, v. 55, n. 13, p.5229-5237, 2007.

BISHOP, M. D. et al. Rapid communication: Restriction fragment length polymorphisms in the bovine calpastatin gene. Journal of Animal Science, v. 71, p. 
$2277,1993$.

BRASIL. Lei 11.105, de 24 de março de 2005. Regulamenta os incisos II, IV e V do $\S 1$ o do art. 225 da Constituição Federal. Diário Oficial [da] República Federativa do Brasil, Brasília, DF, 24 mar. 2005. Disponível em: <http://legislacao.planalto.gov.br/ legisla/legislacao.nsf/Viw_Identificacao/lei $\% 20$ 11.105-2005?OpenDocument>. Acesso em: 11 mar. 2014.

BUCHANAN F. C. et al. Association of a missense mutation in the bovine leptin gene with carcass fat content and leptin mRNA levels. Genetic Selection Evolution v. 34, p. 105-116, 2002.

\section{CAÑEQUE, V.; SAÑUDO, C. Estandarización} de lãs metodologias para evaluar la calidad del producto (animal vivo, cal, carne y grasa) em los rumiantes. Monografias Del Instituto Nacional de Investigación y Tecnologia Agrária y Alimentaria. Serie Ganadera, n ${ }^{\circ} 3$ - 2005. Madrid, España. 448 páginas, 2005. ISBN 84-7498-509-9.

CASAS, E. et al. Assessment of single nucleotide polymorphisms in genes residing on chromosomes 14 and 29 for association with carcass composition traits in Bos indicus cattle. Journal of Animal Science, v. 83, p. 13-19, 2005.

CASAS, E. et al. Effects of calpastatin and $\mu$-calpain markers in beef cattle on tenderness traits. Journal of Animal Science, v. 84, n. 3, p. 520-525, 2006.

CASSAR-MALEK, I. et al. Application of gene expression studies in livestock production systems: a European perspective. Australian Journal of Experimental Agriculture, v. 48, p. 701-710, 2008.

CHUNG, H.Y.; DAVIS, M.E.; HINES, H.C. Genetic variation detected by PCR-RFLP in intron 6 of the bovine calpastatin gene. Animal Genetics, v. 32, p. 53-53, 2001a.

CHUNG, H.Y.; DAVIS, M.E.; HINES, H.C. Relationship of two PCR-RFLP in the bovine calpastatin gene with calpastatin activity, meat tenderness and carcass traits. Research and Reviews: Beef and Sheep , v.181, p.29-34, 2001b. (OARDC Special. Circular, 181-01).

CORVA P. et al. Association of CAPN1 and CAST gene polymorphisms with meat tenderness in Bos taurus beef cattle from Argentina. Genetics and
Molecular Biology, v. 30, p. 1064-1069, 2007.

COSTELLO S. et al. Association of polymorphisms in the calpain I, calpain II and growth hormone genes with tenderness in bovine $\mathrm{M}$. longissimus dorsi. Meat Science, v. 75, p. 551-557. 2007.

CURI, R. A. et al. Alternative genotyping method for the single nucleotide polymorphism A2959G (AF159246) of the bovine CAST gene. Pesquisa Agropecuária Brasileira, v. 43, n. 5, p. 657-659, 2008.

DRANSFIELD, E. Modeling postmortem tenderization. IV - Role of calpain and calpastatin in conditioning. Meat Science, v. 34, n. 2, p. 217- 234, 1993.

FINK, A. L. Chaperone-mediated protein folding. Physiology review, v. 79, n. 2, p. 425-442, 1999.

FRYLINCK, L. et al. Evaluation of biochemical parameters and genetic markers for association with meat tenderness in South African feedlot cattle. Meat Sience, v. 83, p. 657-665, 2009.

GEARY T. W. et al. Leptin as a predictor of carcass composition in beef cattle. Journal of Animal Science, v. 81, p. 1-8, 2003.

GEESINK, G. H. $\mu$-Calpain is essential for postmortem proteolysis of muscle proteins1,2. Journal Animal Science, v. 84, p. 2834-2840, 2006.

GOLL, D. E. et al. Role of the calpain system in muscle growth. Biochimie, v. 74, p. 225-237, 1992.

GOLL, D. E. et al. The Calpain System. Physiological Reviews, v. 83, p. 731-801, 2003.

GUILLEMIN, N. et al. Functional analysis of beef tenderness. Journal of Proteomics, v. 75, p. 352-365, 2011.

GUO, D. et al. Proteomic analysis of SUMO4 substrates in HEK293 cells under serum starvation-induced stress. Biochemical and Biophysical Research Communications, v. 337, p. 1308-1318, 2005.

HAEGEMAN, A.; VAN ZEVEREN, A.; PEELMAN, L. J. New mutation in exon 2 of the bovine leptin gene. Animal Genetics, v. 31, p. 70, 2000.

HOCQUETTE, J. F. et al. Recent advances in cattle functional genomics and their application to beef quality. Animal, v. 1, p. 159-173, 2007. 
GRIGORIAN, M. et al. Tumor suppressor p53 protein is a new target for the metastasis-associated Mts1/S100A4 protein - Functional consequences of their interaction. Journal of Biological Chemistry, v. 276, p. 22699-22708, 2001.

LARA, M. A. C. et al. Leptin gene polymorphism (SNP305) in cattle and its relationship in the tenderness of the meat. Actas Iberoamericanas de Conservación Animal, v. 1, p. 195-198, 2011.

LEE, S. et al. Effect of ion fluid injection on beef tenderness in association with calpain activity. Meat Science, v. 56, p. 301-310, 2000.

LISA, C.; DI STASIO, L. Variability of m-Calpain and Calpastatin genes in cattle. Italian Journal of Animal Science, v. 8, p. 99-101, 2009.

LONERGAN, S. M. et al. Relationship of restriction fragment length polymorphisms (RFLP) at the bovine calpastatin locus to calpastatin activity and meat tenderness. Journal of Animal Science, v. 73, p. 3608-3612, 1995.

MORRIS, C. A. et al. Genotypic effects of calpain 1 and calpastatin on the tenderness of cooked M. longissimus dorsi steaks from Jersey $\times$ Limousin, Angus and Hereford-cross cattle. Animal Genetics, v. 37, p. 411-414, 2006.

OUALI, A. et al. Revisiting the conversion of muscle into meat and the underlying mechanisms. Meat Science, v. 74, p. 44-58, 2006.

PAGE, B. T. et al. Evaluation of single nucleotide polymorphisms in CAPN1 for association with meat tenderness in cattle. Journal of Animal Science, v. 80, p. 3077-3085, 2002.

PAGE, B. T. et al. Association of markers in the bovine CAPN1 gene with meat tenderness in large crossbred populations that sample influential industry sires. Journal of Animal Science, v. 82, p. 34743481, 2004.

PICARD, B. et al. Skeletal muscle proteomics in livestock production. Briefings in functional genomics, v. 9, n. 3, p. 259-278, 2010.

PINTO, L. F. B. et al. Association of SNPs on CAPN 1 and CAST genes with tenderness in Nellore cattle. Genetics and Molecular Research, v. 9, n. 3, p. 1431$1442,2010 b$.
RENAND, G. et al. Relationships between muscle characteristics and meat quality traits of young Charolais bulls. Meat Science, v. 59, p. 49-60, 2001.

RIBECA, C. et al. Association of polymorphisms in calpain $1,(\mathrm{mu} / \mathrm{I})$ large subunit, calpastatin, and cathepsin $\mathrm{D}$ genes with meat quality traits in double-muscled Piemontese cattle. Animal Genetics, v. 44, n. 2, p. 193-196, 2013.

SCHENKEL, F. S. et al. Association of a single nucleotide polymorphism in the calpastatin gene with carcass and meat quality traits of beef cattle. Journal of Animal Science, v. 84, p. 291-299, 2006.

SUN, Y.; MACRAE, T. H. Small heat shock proteins: molecular structure and chaperone function. Cellular and Molecular Life Sciences, v. 62, p. 2460-76, 2005.

WHITE S. N. et al. A new single nucleotide polymorphism in CAPN1 extends the current tenderness marker test to include cattle of Bos indicus, Bos taurus, and crossbred descent. Journal of Animal Science, v. 83, n. 9, p. 2001-2008, 2005.

YANG, X. L. et al. Proteomic Dissection of Cell Type-Specific H2AX-Interacting Protein Complex Associated with Hepatocellular Carcinoma. Journal of Proteome Research, v. 9, p. 1402-1415, 2010.

YOU, J. et al. Treatment with the Proteasome Inhibitor MG132 during the End of Oocyte Maturation Improves Oocyte Competence for Development after Fertilization in Cattle. PloS one, v. 7, n. 11, p. e48613, 2012.

SAÑUDO, C.; JIMENO, V.; CARVIÑO, M. Producción de ganado vacuno de carne y tipos comerciales en España. Schering-Plough Animal Health, Zaragoza, Espanha, 2008. ISBN 978-84-691-2300-3. 308 p.

United States Department of Agriculture (USDA). Livestock an Poultry: Word Markets and Trade. World Exports 2013 Revised: Broiler Meat Higher, Beef Lower and Pork Unchanged. Washington, D.C. 2013. Disponível em: <http://www.fas.usda.gov/ psdonline/circulars/livestock_poultry.pdf $>$. Acesso em 9 de jun. 2013. 